\title{
Arte y Diseño, semejanzas y diferencias
}

\author{
M.E. Mónica del Carmen Aguilar Tobin \\ monica.aguilar@unison.mx \\ Universidad de Sonora \\ M.E. Andrés Abraham Elizalde García \\ andres.elizalde@unison.mx \\ Universidad de Sonora
}

Mucho se ha escrito acerca de la diferencia entre arte y diseño, argumentos de grandes voces en la materia han ido y venido a través de los años, y hasta la fecha no se ha logrado una postura unificada acerca del tema. Este escrito no pretende establecerla tampoco, sino exponer los principales puntos de vista adentrándose en las definiciones y las pretensiones de cada uno, sólo así podremos situar esa delgada línea que separa estos dos conceptos, poniendo de manifiesto aquellas similitudes y poder incorporarlas y convertirlas en actividades comunes para ambas disciplinas.

¿Qué tienen en común y qué diferencía al arte y al diseño? Para poder responder esta pregunta es necesario conocer las definiciones de cada uno, así como sus fines, y para esto podemos encontrar tantas respuestas como ángulos puede tener la perspectiva. Las definiciones de arte varían a través del tiempo, la cultura y la subjetividad, luego, cada movimiento, estilo y corriente artística define al arte desde su propia trinchera. A pesar de este amplio abanico de posibilidades, el arte suele estar siempre asociado al concepto de belleza.

\section{El arte}

El concepto de arte en su acepción original, no va ligada a la idea de lo bello, significa literalmente pericia o habilidad para hacer algo, el dominio de la técnica. Lo artístico es, lo "artificial”, lo hecho por el hombre. De aquí que puede hablarse de "un arte feo". Es hasta un segundo momento cuando la idea de arte se asocia a la de belleza: el surgimiento de las "bellas artes". Si la idea de arte llevara implícita la idea de belleza, la expresión "Bellas Artes" sería una redundancia.

Leonardo da Vinci afirmaba que : "A veces se entiende por arte la técnica, sin embargo, mientras que a la técnica se llega por medio de la constancia y por la voluntad, al arte se llega por el acercamiento de la perfección interna, esa perfección del alma que no tiene metas para medirse ni métodos racionales para explicarlo, porque está más allá de la materia y razón.” Más allá de concebir el arte como esa perfección en el dominio de algo, definiciones como la de la RAE (2018) lo definen como una actividad humana mediante la cual se interpreta la realidad o se plasma lo imaginado con recursos plásticos, lingüísticos o sonoros.

Históricamente se ha podido observar que el arte es una expresión libre del artista, en la que puede satisfacer su necesidad de plasmar sentimientos, frustaciones, humor, y cualquier tipo de expresión que sea posible, que en ciertas circunstancias se realiza bajo alguna solicitud específica. Es durante el renacimiento se comienza a hacer la distinción entre el artesano, como productor de diversos tipos de obras, y el artista, como productor de obras únicas, $\mathrm{y}$ es en el siglo XIX que surge el concepto 
de Artes Plásticas, para diferenciarlas de las Artes Escénicas.

A mediados del siglo XIX, artistas pintores principalmente de París, como Toulouse-Lautrec comenzaron a crear carteles con fines comerciales. El cartel como sustituto del lienzo del pintor, es el primer ejemplo de lo que se llamó "arte publicitario" . Es en este momento cuando esta actividad comenzó con el desarrollo de una de las disciplinas que más adelante se llamó diseño. Durante el siglo XX las artes plásticas tuvieron que dar cabida al video, al arte digital y a la fotografía, y a nuevas propuestas como el grafiti y el arte urbano, por lo que se comenzó a utilizar el término "artes visuales" para poder dar cabida a estas nuevas áreas.

\section{El diseño}

Victor Papanek (1971) en su polémica obra Diseñar para el mundo real define al diseño como: "el esfuerzo consciente para establecer un orden significativo", que bien se puede aplicar a toda actividad humana, ya que desde maquetar un libro, planificar un mural o bocetar un cartel, preparar un platillo o criar un hijo también requieren de este esfuerzo consciente.

Pero definiendo al diseño como actividad proyectual, se puede afirmar que todo diseño es fruto de un designio, tiene como objetivo cubrir una función para solucionar un problema o mejorar la calidad de vida de la gente.

De acuerdo al International Council of Societies of Industrial Design, el diseño es una actividad creativa cuyo propósito es establecer las cualidades multifacéticas de los objetos, procesos, servicios y sus sistemas, a lo largo de todo el ciclo de vida de los mismos. (López, 2018, p. 11) El concepto del diseño en la Bauhaus, fue orientado a fundamentos teóricos que se pretedrían universalizar, funamentos funcionalistas, siempre regidos por la famosa frase "la forma le sigue a la función". Mientras que el concepto tradicional del diseño lo define como "una actividad proyectual, en la que se creaban objetos, mediante un código formal preciso, con un lenguaje único, universal e internacional, en el que se daba gan importancia al manejo de medios gráficos como el dibujo y el boceto, con una plástica impersonal, desornamentada y depuradamente geométrica, con lo que se pretedía llegar a un mundo objetual, visualemnete más democrático, armonioso y funcional". (López, 2018, p. 18)

"Sin embargo, en la actualidad no nos podemos quedar con este concepto aislado de diseño, ya no es posible usar las mismas herramientas conceptuales tradicionales, la complejidad puede ayudar a tener una visión más próxima de lo que sucede en el campo del diseño, pues ésta se centra en resolver problemas de diseño reales en proyectos concretos con el apoyo del pensamiento complejo, a través del cual se pueden buscar estrategias y conseguir porpuestas con soluciones originales e innovadoras". (López, 2018, p. 21)

Por otra parte, el arte puede tener o no una eficiencia en su mensaje, (a veces el artista se esfuerza para que no todos entiendas su sistema de comunicación y sólo unos privilegiados lo pueden hacer) y no por eso deja de funcionar como arte, al contrario de lo que sucede con el diseño ya que, al no tener un sistema eficiente de comunicación, se afirma que "el diseño no funciona".

André Ricard (2004) afirma que: "De todas las ramas del diseño, el gráfico es el que expresa en sus obras de manera más evidente su relación con las artes plásticas puesto que, al igual que la pintura utiliza imágenes, colores y signos de todo tipo como medio de expresión y de significación." (Calvera, 2004, p. 91)

Lupton (2016, p. 8 ), nos hace referencia a diferentes tipos de habilidades que se deben desarrollar en el diseñador como son habilidades conceptuales, técnicas, críticas, sociales y profesionales, todas 
ellas para formas un profesionista eficaz y menciona que no enseñamos arte, sino a estudiantes de arte y comenta que "No podemos enseñar a la gente a ser genios (aunque, afortunadamente, nuestros estudiantes son muy, muy talentosos), pero podemos enseñarles habilidades. Corresponde a ellos a poner esas habilidades a trabajar".

Dentro de las necesidades del diseño, podemos observar que el interés puede mover también los materiales que se van a utilizar, no es independiente de este aspecto el arte, pero no se limita a que se pueda realizar o no con determinado material; el diseño retoma aspectos como la sustentabilidad, ergonomía y costos para decidir si es conveniente utilizarlo de una mejor manera, de acuerdo a un público determinado, cumpliendo una función específica.

\section{Convergencias y divergencias.}

Los fines del arte y del diseño parecen establecer una separación importante entre ambas disciplinas, debido a que antes de la producción en serie de los objetos, las artes plásticas tenían como objetivo crear piezas únicas para un sector privilegiado, elitista, para el cual el precio no era relevante.

A mediados del siglo XIX, la revolución industrial deja un lugar para que el diseño emerja para diseñar objetos que posean características apegadas a la estética de modo que los compradores voltearan a verlos, pero con el fin de que cubrieran necesidades comunes a precios accesibles.

Donis A. Dondis en su libro Sintaxis de la Imagen (Dondis, 2003, p.18) aborda la clasificación de las artes visuales en bellas artes y artes aplicadas (área donde sitúa al diseño), tomando como factor de diferenciación la utilidad y la estética. La utilidad, afirma Dondis, "designa el diseño y la fabricación de materiales, objetos y aquello que responde a las ne- cesidades básicas, para cubrirlas necesita herramientas, fabricar recipientes, protegerse del entorno, construir un habitat. Todo miembro de la comunidad, además de producir, se vale del diseño para darle una expresión única a su trabajo.

Muy a menudo, se habla del diseño como si fuera un estilo artístico determinado, el público menciona "sillas de diseño", "lámparas de diseño" como si el resto de estos artículos no hubiera pasado por un proceso de diseño. Es en esta aproximación, donde André Ricard (Calvera, 2004, p. 94) plantea si este diseño "de autor" puede ser visto como arte. El functional art se asemeja al disñeo en el hecho de que el artista utiliza objetos funcionales como lienzo, aquí, el arte y el diseño parten de puntos diferentes para llegar a significados similares.

En el diseño, a diferencia de lo que ocurre con el arte, los resultados pueden llegar a expresar la sensibilidad del autor, pero sin llegar a intervenir en la función. La carga expresiva puede ser un efecto colateral, pero nunca una finalidad.

La creatividad como factor común.

Vemos en la creatividad una especie de magia que ilumina el pensamiento y nos hace imaginar, producir, dibujar y crear, y asumimos que es un punto en común entre el arte y el diseño. Rivera (s.f.), menciona en "Del arte, Fontana y ciertas implicaciones pedagógicas" a la actividad del diseño gráfico como un saber práctico en el campo de la retórica, lo define como una técnica (techné), cuya traducción lo coloca dentro del terreno del arte (ars). Coloca a la técnica como uno de los tres procesos necesarios para crear obras: la disposición natural, el azar y el arte; y es precisamente el arte el que nos permite que el diseño alcance un estado artístico en la medida de planear una serie de acciones para lograrlo, incluyendo experiencia y la imitación hasta llegar un modelo, mismo que se alcanza mediante la práctica. Podemos asumir entonces 
que este proceso sucede en los procesos creativos y son, en todo caso, similitudes entre los dos procesos.

No hay arte sin el razonamiento o voluntad sobre las experiencias, entonces son necesarias las experiencias para lograr el arte, el cual se logra con las acciones de la voluntad del mismo modo que sucede en el diseño. No hay teoría sin práctica ni práctica sin teoría. Dentro del campo del diseño es necesario profundizar sobre esa experiencia de comunicar y formular teorías sobre cómo se puede practicar, por lo tanto, la actividad se convierte en precisa, calculadora, tal vez exacta para que el público no tenga una ambigüedad en lo que observa, de ser así, no se estaría cumpliendo con la función comunicativa del diseño.

\section{Conclusiones}

El campo del diseño construye un discurso donde por momentos se opone y en otros se identifica con el arte, genera movimientos temporales de inclusión y exclusión. Por su parte, el arte se resiste a incluir al diseño como parte del arte, es una discusión inacabada e inacabable.

Pero de la misma manera que el arte influye en el diseño, ocurre a la inversa, ya que todas las imágenes que este último crea y que se vuelven presentes en todo momento de la vida cotidiana, influyen en la creación artística. El diseño alimenta al arte y el arte inspira al diseño.

\section{Bibliografía}

Borobio, L. (2015). Definiendo el arte. Revista Universidad Pontificia Bolivariana, 33(114-115), 160 - 168. Recuperado de https://revistas.upb.edu.co/index.php/ upb/article/view/4425/3990

Calvera Anna (2004) Arte ¿'? Diseño. Ed. G. Gili. Barcelona.

Dondis, Donis A. (2003) Sintaxis de la imagen. Introducción al alfabeto visual. Ed. G. Gili. Barcelona.

Guillen, Jesús C.. (2015). ¿Por qué el cerebro humano necesita el arte?. Dicembre 7 de 2018, de Neurociencia Sitio web: https://escuelaconcerebro.wordpress. com/2015/01/31/por-que-el-cerebro-humano-necesita-el-arte/

Lupton, E. (2016) El diseñador como productor. Potenciando las habilidades del estudiante. Diciembre 10 de 2018, de Ars Optika Editores. Sitio web: http://arsoptikaeditores.com.mx/sites/default/files/ArsLibers/AO-05-Dos-Ensayos_0.pdf

Rivera, L. (2005) “Del Arte, Fontana y ciertas implicaciones pedagógicas". En: Unidad y Diversidad. Revista Interdisciplinaria de divulgación. Vol. 4, \#2, México, Universidad Intercontinental.

Rabkin N. y Redmond R. (2004). Putting the arts in the picture: reforming education in the 21st century. Columbia College

Sousa, David A. (2011). How the brain learns. Corwin.

Winner E. et al. (2006): "Studio thinking: how visual arts teaching can promote disciplined habits of mind". En Locher P. et al. (Eds), New directions in Aesthetics, Creativity, and the Arts. Baywood. 